ENCYCLOPEDDIE Encyclopédie berbère

BERBERE

$6 \mid 1989$

6 | Antilopes - Arzuges

\title{
Aouker (Awker)
}

R. Mauny

\section{(2) OpenEdition}

Journals

Édition électronique

URL : http://journals.openedition.org/encyclopedieberbere/2557

DOI : 10.4000/encyclopedieberbere.2557

ISSN : 2262-7197

\section{Éditeur}

Peeters Publishers

\section{Édition imprimée}

Date de publication : 1 janvier 1989

Pagination : 803-804

ISBN : 2-85744-324-2

ISSN : 1015-7344

\section{Référence électronique}

R. Mauny, «Aouker (Awker) », Encyclopédie berbère [En ligne], 6 | 1989, document A239, mis en ligne le 01 décembre 2012, consulté le 15 octobre 2020. URL : http://journals.openedition.org/ encyclopedieberbere/2557 ; DOI : https://doi.org/10.4000/encyclopedieberbere.2557

Ce document a été généré automatiquement le 15 octobre 2020

(c) Tous droits réservés 


\section{Aouker (Awker)}

\section{R. Mauny}

1 Régions de grandes dunes à demi fixées, au sud de la Mauritanie, au Trarza et entre le Hodh et la falaise de Tichit-Walata. La première mention en est d'Al-Bakri (1067), rapportant qu'Awkar est le nom du pays de Ghana. En pays touareg, de Foucauld (1940, p. 194) signale plusieurs vallées ou plaines de ce nom, dans les Ajjers, l'Atakor, l'Aïr et entre Ahaggar et Aïr. Doujat d'Empeaux et P. Laforgue, 1923, en parlent comme d'une « région de dunes fixées», le Cap. Brosset, 1939, p. 661, comme d' « ergs steppiens». R. Capot-Rey en fait l'équivalent tamacheq du draa arabe = bras de dune (Trav. Inst. rech. sahar., IV, 1947, p. 88), mais aussi de «vallée, terrain très accidenté, dédale de crêtes rocheuses et de bras d'erg» (1955, p. 106). Tous les auteurs (sauf F. Nicolas, 1953, p. 331, qui rapproche le mot Aukar du wolof Kör =maison, village, hameau, rappelant que « les Proto-Wolof ont habité ce coin ", étymologie qui est peu soutenable) en donnent une origine berbère : de Foucauld, 1940, p. 194 ; Capot-Rey, 1947, p. 88 ; A. Leriche, 1955, p. 15 (Awkar, du zénaga Ewger, vaste dune, Th. Monod, 1958, p. 311). 
La dépression de l'Aouker et les reliefs qui la bordent. Carte de S. Daveau.

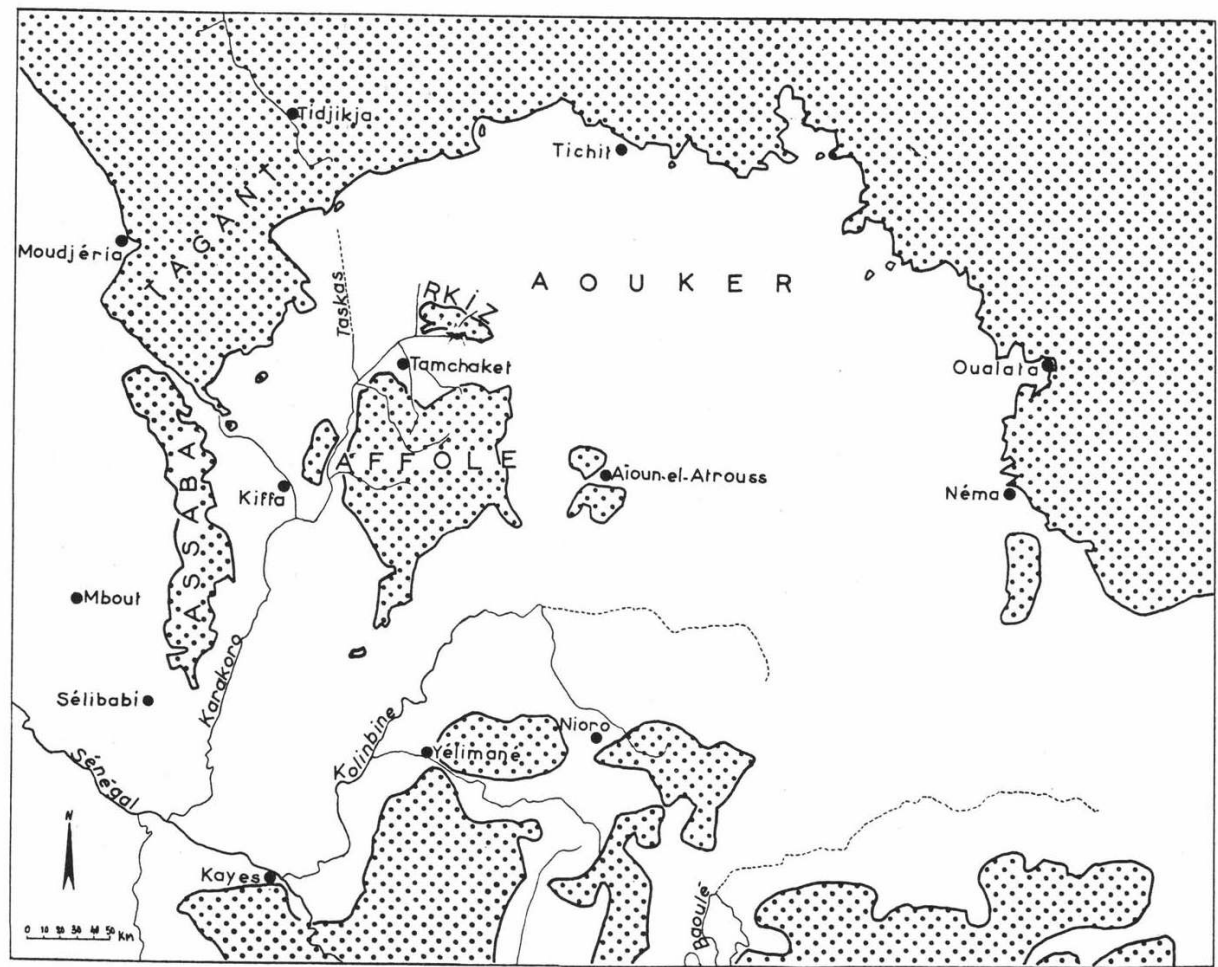

\section{BIBLIOGRAPHIE}

Brosset Cap. D., « Essai sur les ergs du Sahara occidental», B. IFAN, I, n 4, 1939, pp. 657-690.

Capot-Rey R., Le Sahara français, Paris, PUF, 1953, 564 p. - « Un glossaire des termes géographiques arabo-berbères», Alger, Bull, liaison sahar., n² 21, nov. 1955.

Doujat d'Empeaux et P. Laforgue, Un itinéraire saharien, Auch, 1923, 6 p.

El-Bekri, Description de l'Afrique septentrionale, trad. M.G. de Slane, Alger, Jourdan, 1913, 407 p.

Foucauld P. de, Dictionnaire abrégé touareg-fançais, Basset, Paris, Larose, 1940, 363 p.

Leriche A., « Terminologie géographique maure. Saint-Louis», Et. maurit., n 6, 1955, 73 p.

Monod Th., « Majâbat al-Koubra», Dakar, Mém. IFAN, n 52, 1958, 407 p.

Nicolas F., « La langue berbère de Mauritanie», Dakar, Mém. IFAN, 1953, 476 p.

\section{INDEX}

Mots-clés : Géographie, Mauritanie, Sahel 